Archived version from NCDOCKS Institutional Repository http://libres.uncg.edu/ir/asu/

\title{
Appalachïan
}

$\overline{B \text { O O N E, N O R T H C A R O L I N A }}$

\section{Flowers Are An Important Food For Small Apes In Southern Sumatra}

\author{
By: Susan Lappan
}

\begin{abstract}
Flowers are included in the diets of many primates, but are not generally regarded as making an important contribution to primate energy budgets. However, observations of a number of lemur, platyrrhine, and cercopithecine populations suggest that some flower species may function as key primate fallback foods in periods of low abundance of preferred foods (generally ripe fruits), and that flowers may be preferred foods in some cases. I report heavy reliance on flowers during some study months for a siamang (Symphalangus syndactylus) population in southern Sumatra. Siamangs at Way Canguk spent $12 \%$ of feeding time eating flowers from October 2000 to August 2002, and in 1 month flower - feeding time exceeded $40 \%$ of total feeding time. The overall availabilities of fig and nonfig fruits, flowers, and new leaves in the study area were not significant predictors of the proportion of time that siamangs spent consuming any plant part. However, flower - feeding time was highest in months when nonfig fruit - feeding time was lowest, and a switch from heavy reliance on fruit to substantial flower consumption was associated with a shift in activity patterns toward reduced energy expenditure, which is consistent with the interpretation that flowers may function as a fallback food for Way Canguk siamangs. Hydnocarpus gracilis, a plant from which siamangs only consume flowers, was the third - most - commonly consumed plant at Way Canguk (after Ficus spp. and Dracontomelon dao), and flowers from this plant were available in most months. It is possible that relatively high local availability of these important siamang plant foods is one factor promoting high siamang density in the study area.
\end{abstract}

Lappan, S. (2009), Flowers Are an important food for small apes in southern Sumatra. Am. J. Primatol., 71 : 624-635. doi:10.1002/ajp.20691. Publisher version of record available at: https://onlinelibrary.wiley.com/ doi/10.1002/ajp.20691 
American Journal of Primatology 71:624-635 (2009)

\title{
RESEARCH ARTICLE
}

\section{Flowers Are an Important Food for Small Apes in Southern Sumatra}

\author{
SUSAN LAPPAN* \\ Division of Ecoscience, Ewha University, Seoul, Republic of Korea
}

Flowers are included in the diets of many primates, but are not generally regarded as making an important contribution to primate energy budgets. However, observations of a number of lemur, platyrrhine, and cercopithecine populations suggest that some flower species may function as key primate fallback foods in periods of low abundance of preferred foods (generally ripe fruits), and that flowers may be preferred foods in some cases. I report heavy reliance on flowers during some study months for a siamang (Symphalangus syndactylus) population in southern Sumatra. Siamangs at Way Canguk spent $12 \%$ of feeding time eating flowers from October 2000 to August 2002, and in 1 month flower-feeding time exceeded $40 \%$ of total feeding time. The overall availabilities of fig and nonfig fruits, flowers, and new leaves in the study area were not significant predictors of the proportion of time that siamangs spent consuming any plant part. However, flower-feeding time was highest in months when nonfig fruit-feeding time was lowest, and a switch from heavy reliance on fruit to substantial flower consumption was associated with a shift in activity patterns toward reduced energy expenditure, which is consistent with the interpretation that flowers may function as a fallback food for Way Canguk siamangs. Hydnocarpus gracilis, a plant from which siamangs only consume flowers, was the thirdmost-commonly consumed plant at Way Canguk (after Ficus spp. and Dracontomelon dao), and flowers from this plant were available in most months. It is possible that relatively high local availability of these important siamang plant foods is one factor promoting high siamang density in the study area. Am. J. Primatol. 71:624-635, $2009 . \quad$ (c) 2009 Wiley-Liss, Inc.

\section{Key words: siamang; gibbon; flowers; fallback food; diet}

\section{INTRODUCTION}

Most primate species are selective feeders, displaying a pronounced preference for a specific subset of the food species available in their habitats, many of which are only seasonally available. In particular, ripe fruits are very patchily distributed in time and space. Therefore, primates relying heavily on ripe fruits may experience challenges in consistently obtaining enough energy for survival and reproduction. Accordingly, the importance of fallback foodsfoods that animals use during periods when the availability of preferred foods is low-has been widely acknowledged [e.g. Lambert, 2007b; Marshall \& Wrangham, 2007]. Fallback foods are typically abundant, but lower in quality or more difficult to harvest than preferred foods. Seasonal reliance on these foods may allow ripe-fruit specialists to survive during periods of low fruit availability. Although descriptions of primate diets are usually based on the mostfrequently consumed foods (i.e., animals that eat mostly fruits and leaves are described as frugivore-folivores), less-frequently consumed foods may be critical determinants of survival and reproduction in unstable environments, and may exert strong selection on primate feeding adaptations [Lambert, 2007b; Marshall \& Wrangham, 2007].
Flowers are included in the diets of many primates, but primates rarely spend more than $10 \%$ of annual feeding time eating flowers [Janson \& Chapman, 1999], and generally consume flowers from only a small number of species [Goldizen et al., 1988; Overdorff, 1992]. Although flowers often contain sugary nectars, these nectars are usually dilute and produced in small quantities, making them relatively poor-quality resources for primates [Terborgh, 1983; but see McCabe \& Fedigan, 2007]. Competition for nectars is also high, as nectars are consumed by many specialized competitors, including insects, avians, and bats [Terborgh \& Stern, 1987]. Accordingly, researchers often pay relatively little attention to the flower component of primate

Contract grant sponsors: The Leakey Foundation; Sigma Xi; The Fulbright Student Program; New York University; The New York Consortium for Evolutionary Primatology; The Margaret and Herman Sokol Foundation; Ewha University.

*Correspondence to: Susan Lappan, Division of Ecosciences, Ewha University, 11-1 Seodaemun-gu, Daehyun-dong, Seoul 120-750, Republic of Korea. E-mail: lappan@nyu.edu

Received 17 September 2008; revised 18 March 2009; revision accepted 19 March 2009

DOI 10.1002/ajp.20691

Published online 20 May 2009 in Wiley InterScience (www. interscience.wiley.com). 
diets, lumping flowers into the "other" category, along with other less-frequently consumed foods such as bark, fungus, and sap [Lambert, 2007a]. Although the importance of these "other" foods in providing micronutrients (e.g. vitamins and minerals) is sometimes acknowledged, flowers are rarely considered to be important sources of energy for primates [Lambert, 2007a]. However, the nutritional qualities of flowers vary among plant species, and flowers have some nutritional advantages over fruits, often being higher in protein [McConkey et al., 2003; Simmen et al., 2007], and some primates include a substantial nectar or flower component in their diets in some months, particularly during periods of low availability of preferred fruits [e.g. Ferrari \& Strier, 1992; Goldizen et al., 1988; Ménard \& Vallet, 1997, Overdorff, 1992; Terborgh, 1983; Terborgh \& Stern, 1987], suggesting that flowers may function as fallback foods for some primate species, and may even be preferred foods in some cases.

Gibbons (family Hylobatidae) are arboreal apes inhabiting closed-canopy tropical forests. Most gibbons are primarily frugivorous, but include new leaves, flowers, insects, and other foods in their diets in varying proportions [Bartlett, 2007; Elder, 2009]. Gibbons generally defend small ( $\sim 40 \mathrm{ha}$ ) territories that comprise an average of $82 \%$ of their home ranges [Bartlett, 2007]. The effects of seasonal variation in food availability may be particularly pronounced in animals that defend territories, as these animals will be unable to move into new areas to seek preferred food items during periods of scarcity. Nonetheless, gibbons are selective feeders, displaying a strong preference for fruits with specific features, including soft, juicy pulp, yellow or orange color, thin or rind-like skin, and large crop size [McConkey et al., 2002].

Siamangs (Symphalangus syndactylus) are larger than other gibbon species, which may affect their ability to include lower-quality foods in their diets [Clutton-Brock \& Harvey, 1977; Raemaekers, 1984], and are often reported to be less frugivorous than other gibbons [Elder, 2009; but see Leighton, 1987]. In previous studies, siamangs spent $38-61 \%$ of feeding time feeding on ripe fruits and $17-48 \%$ of feeding time feeding on leaves [Chivers, 1974; MacKinnon \& MacKinnon, 1980; Palombit, 1997; Raemaekers, 1977]. Chivers and Raemaekers [1986] proposed that the proportion of time that siamangs spend eating other foods may depend largely on the local availability of ripe fig (Ficus spp; Moraceae) fruits. Figs tend to fruit asynchronously and to produce large crops of fruit [Janzen, 1979] that have substantially higher calcium levels than other fruits [O'Brien et al., 1998], which make them particularly appealing foods for many tropical frugivores. In previous studies siamangs, like other gibbons, spent very little time feeding on flowers [1-6\% of feeding time; Chivers, 1974; MacKinnon \& MacKinnon, 1980; Palombit, 1997].
I evaluated the diets of five siamang groups at the Way Canguk Research Station in southern Sumatra from 2000 to 2002. Although my results confirmed that siamangs spend most of their time eating ripe fruits and leaves, I found that flowers comprised a substantial component of siamang diets; in some months, some siamang groups spent more time eating flowers than they did eating any other type of food. Here I describe siamang diets at Way Canguk, evaluate the importance of flowers for siamangs at Way Canguk, and discuss the implications of flower feeding for siamangs and their communities. Detailed data reflecting the actual availability of plant foods in the study groups' home ranges are not available, so I was not able to directly test the hypothesis that flowers are fallback foods (i.e., that they are not preferred). However, some preliminary inferences can be drawn from the relationships between flower feeding and other dietary and behavioral variables. I predict that if flowers function as a siamang fallback food, then (a) flower consumption should be negatively associated with the consumption of fig and nonfig fruits and (b) relatively high flower consumption should be associated with changes in activity patterns, such as daily travel distance and feeding time, indicative of an energy-minimizing strategy.

\section{METHODS}

\section{Study Area and Siamang Population}

The Way Canguk Research Area is located in the southern part of the $3,568 \mathrm{~km}^{2}$ Bukit Barisan Selatan National Park on Sumatra, Indonesia. The 900 ha research area is run by the Wildlife Conservation Society-Indonesia Program (WCS-IP) and the Indonesian Ministry of Forestry's Department for the Protection and Conservation of Nature (PHKA). The research area consists of a mosaic of primary lowland rain forest and forest damaged by drought, wind, earthquakes, and fire [O'Brien et al., 2003], and is covered by a grid of trails at $200 \mathrm{~m}$ intervals.

Annual rainfall at Way Canguk is generally from 3,000 to $4,000 \mathrm{~mm}$, but can be as low as $1,600 \mathrm{~mm}$ during droughts associated with El Niño-Southern Oscillation (ENSO) events [Kinnaird \& O'Brien, 2005]. Rainfall in the study area is weakly seasonal, with a short dry season between June and September, but monthly rainfall is generally $>60 \mathrm{~mm}$ in every month [Kinnaird \& O'Brien, 2005]. Although some species produce fruit seasonally, overall fig and nonfig fruit availability from July 1997 to February 2002 did not display a consistent pattern of seasonal variation and the total fruit crop was not significantly related to rainfall [Kinnaird \& O'Brien, 2005]. From October 2000 to December 2001, a mean of $27.8 \pm 1.2$ nonfig fruit trees per hectare and $0.62 \pm 0.04$ strangling fig trees per hectare fruited 
each month [Kinnaird \& O'Brien, unpublished data; Fig. 1].

The study area includes all or part of the home ranges of 36-37 siamang groups, and several habituated groups of wild siamangs at this site have been the subjects of behavioral studies by WCS-IP staff and students since 1998 [O'Brien et al., 2003]. A 165-ha section of the study area was damaged in wildfires associated with an ENSO event in 1997 [O'Brien et al., 2003], but the density of siamangs in undamaged parts of the study area remains high relative to densities reported in the other areas of Sumatra [O'Brien et al., 2004].

\section{Behavioral Data Collection}

Three well-trained field assistants and I collected behavioral data from five habituated siamang groups during sleeping-tree-to-sleeping-tree follows. Detailed information about the study groups has been provided elsewhere [Lappan, 2008, 2009]. Groups were followed on a rotating basis, and each group was followed until each adult in the group had served as a focal animal for 2 days, except during a 6-week period in August-September 2001 and a 5 -week period from December 2001 to January 2002 when no research activities were conducted. We collected behavioral data from group B from October 2000, from groups A and C in November 2000, from group F in February 2001, and from group G in May 2001. Behavioral data were collected from all groups until August 2002.
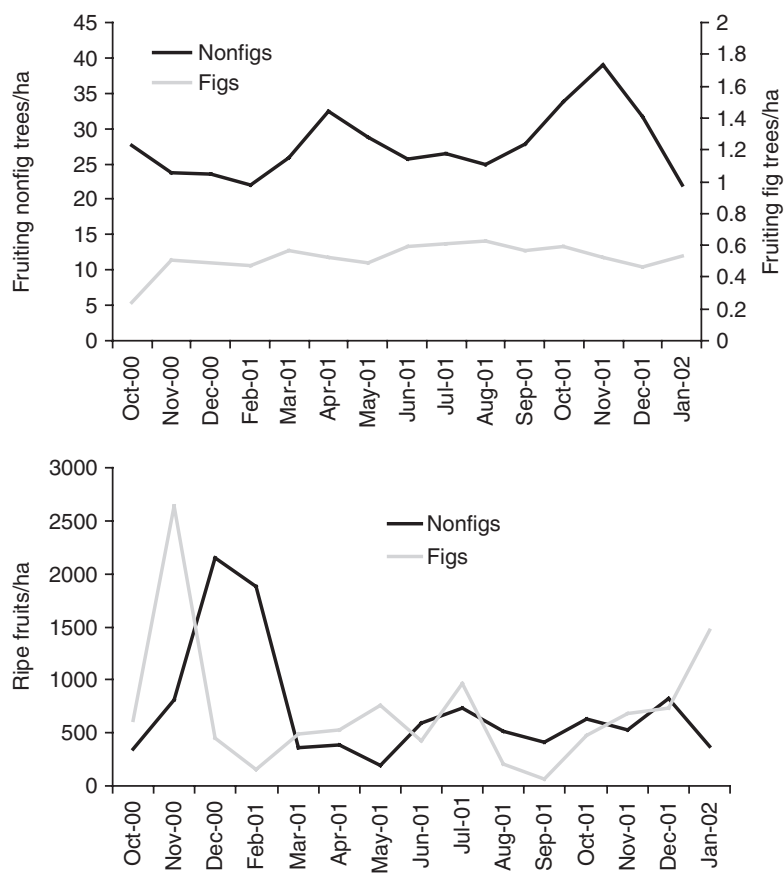

Fig. 1. Estimated mean number of fruiting trees (above) and number of ripe fruits (below) per hectare in the study area.
I chose a focal adult each day on a rotating basis, and a pair of observers collected instantaneous samples of that adult's behavior at 5-min intervals, including activity (e.g. feeding, traveling, resting, etc.) and the estimated distance traveled since the previous instantaneous sample. Only adults were selected as focal animals. Therefore, the diet data may not reflect the full range of food items consumed by individuals of different age classes. When the focal animal was feeding, the plant part and species were recorded. Plant species were identified using the WCS-IP plant library and with the help of Mohammad Iqbal and other WCS-IP staff.

\section{Phenological Data}

Margaret Kinnaird and Tim O'Brien provided unpublished data on the availability of fig fruits, nonfig fruits, new leaves, and flowers in the study area from October 2000 to January 2002. Phenological data for nonfig species were collected from all trees with $>10 \mathrm{~cm} \mathrm{DBH}$ in $10010 \times 50 \mathrm{~m}$ vegetation plots, and phenological data for figs were collected along a $7.8 \times 0.1 \mathrm{~km}$ transect. Trees in the vegetation plots and transects were monitored monthly, and the presence or absence of fruits, flowers, and new leaves was recorded. For fruiting trees, the total fruit crop for each tree was estimated using Leighton's [1993] exponential scale and the percentage of the crop that was ripe was estimated. For additional information about phenological data collection, see Kinnaird and O'Brien [2005]. The relationship between overall availability of each plant part in the study area and consumption of that part by siamangs was examined separately for each group using Spearman correlation analysis of the relationship between the mean proportion of feeding time that adults spent feeding on the plant part and the mean proportion of trees displaying the plant part in the same month (for leaves and flowers), or both the mean proportion of trees producing ripe fruit and the estimated total ripe-fruit crop (for fig and nonfig fruits).

Phenological data were available from 17 individuals of the species Hydnocarpus gracilis (pai$\tan$ ). However, the sex of individual trees was not recorded during phenological data collection. As siamangs only ate flowers from male paitan trees, I excluded trees that I could identify as female (based on fruit production), and assumed that the flowering patterns of males and females were similar in the remaining sample. I estimated the density of males based on the assumption of an approximately equal sex ratio.

\section{Statistical Analyses}

I combined data from all adults in each group for all analyses, and excluded hours from which $<25 \%$ of data were available. I estimated the proportion of time spent in each activity as the proportion of 
instantaneous samples in which the focal animal was observed engaging in that activity. For statistical analyses of behavioral data, I used daily values for daily path length (DPL), daily means of hourly rates for total feeding time (days from which $>2 \mathrm{hr}$ of data are missing were excluded) or monthly means of daily means of hourly rates (for other analyses). The terms "flower-feeding time" and "nonfig fruit-feeding time" are used to indicate the proportion of feeding time spent eating flowers or nonfig fruits. In descriptions of the study population in general, the data presented are means of group means (calculated as means of monthly means for each group) \pm SE. Proportional data were arcsine-square root transformed before the application of parametric statistical tests.

The research protocol for this study was approved by the University Animal Welfare Committee at New York University. Permission to conduct research in Indonesia was granted by the Indonesian Institute of Sciences (LIPI), and permission to conduct research in the Bukit Barisan Selatan National Park was provided by the PHKA. This research was conducted in full compliance with the laws of the Republic of Indonesia.

\section{RESULTS}

\section{Siamangs at Way Canguk Spent Considerable Time Eating Flowers in Some Months}

Table I summarizes the behavioral data available from each group. Siamangs at Way Canguk spent a mean of $0.12 \pm 0.02$ of their feeding time eating flowers (Fig. 2), and were observed eating flowers in 15 of the 19 months for which data from at least two groups are available. Flowers of several species were consumed, but flowers from males of the dioecious plant species $H$. gracilis (Flacourtiaceae), locally known as "paitan," were of disproportionate importance: $56 \%$ of flowerfeeding observations throughout the study period, and up to $100 \%$ of observations in the months of heaviest flower consumption, were of paitan flowers. Other plants from which flowers were eaten included various lianas (20\%), Mitrepora polypirena (5.5\%), Pterospermum javanicum (3.2\%), Celtis rigiscens (2.2\%), and Michelia champaca (1.3\%).

Flower-feeding time differed significantly among study months for four groups (group B: $F_{14,72}=3.464$, $P<0.001$; group C: $F_{15,75}=3.261, P<0.001$; group $\mathrm{F}$ : $F_{14,52}=9.218, \quad P<0.001 ;$ group $\mathrm{G}: F_{9,39}=13.792$, $P<0.001)$. The highest flower-feeding times were recorded in March 2002, when the mean proportion of flower-feeding time in the study population was $0.43 \pm 0.10$ (for groups B, C, F, and G). Behavioral data were not available from group A in March 2002, but the highest flower-feeding time in group A (0.24) was recorded in February 2002. All the five groups had also displayed a slight lower peak in flower feeding between May and July 2001 (Fig. 3).

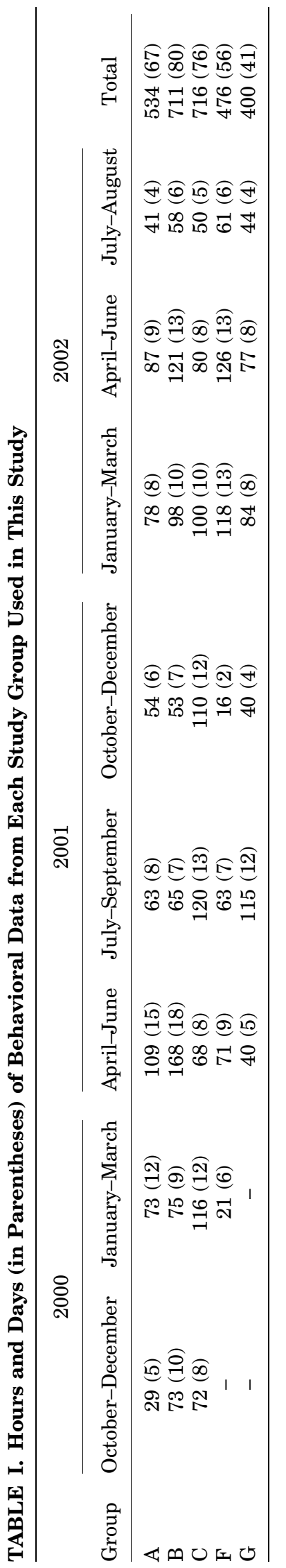




\section{H. gracilis (Paitan) Flowers were the Third- Most-Commonly Consumed Siamang Plant Food}

Figs were the most-commonly consumed plants at Way Canguk. Siamangs ate fig fruits, leaves, and

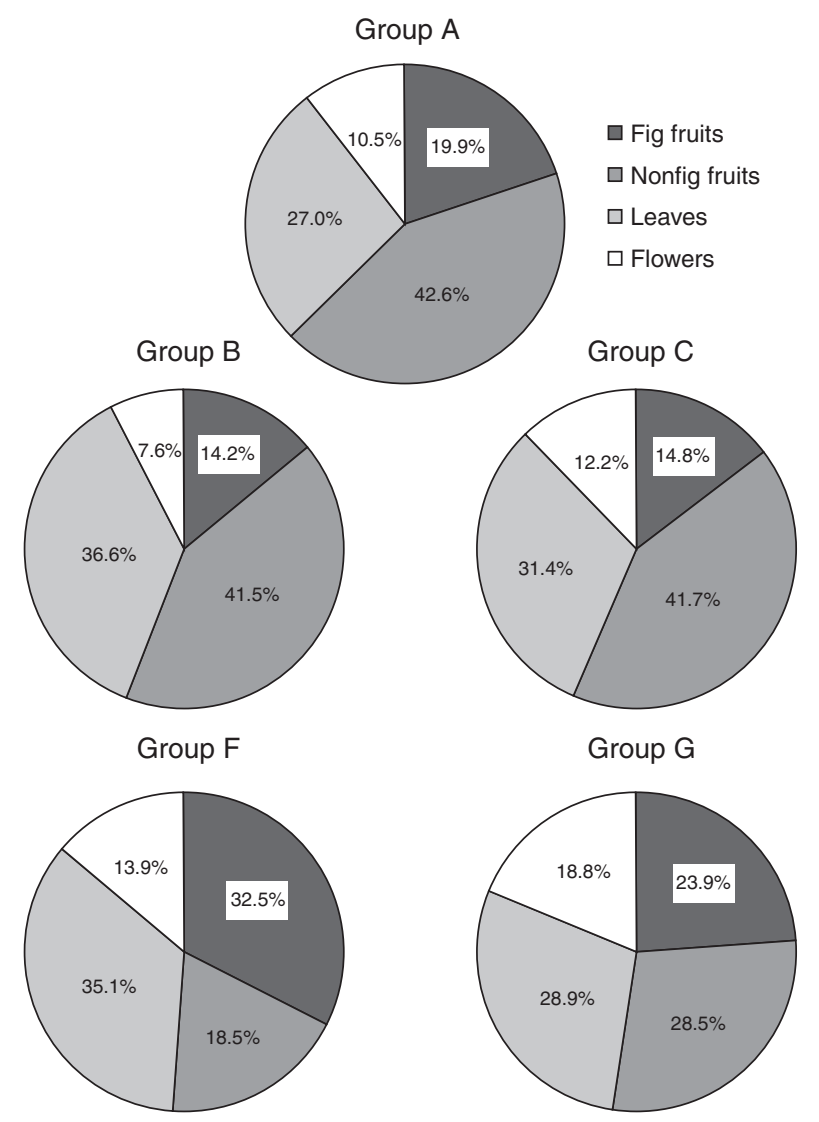

Fig. 2. Diets of adults in siamang study groups A, B, C, F, and G, calculated as percentages of total feeding time spent eating each food type. Insects comprised $\ll 1 \%$ of the diet of each group. flowers, but the majority of feeding observations for figs involved ripe fruits. Overall, siamangs spent a greater mean proportion of feeding time eating parts of fig plants (mean $=0.20 \pm 0.03$ ) than any other plant, and spent $0.17 \pm 0.02$ of feeding time eating fig fruits (Fig. 2). Siamangs were observed feeding on fig fruits in every month of the study (Fig. 4).

After fig fruits, the second-most-commonly consumed food was fruits of the species Dracontomelon dao (Anacardiaceae), locally known as "rao". Rao trees fruit synchronously at Way Canguk and fruit is available for 5-6 months of the year [O'Brien et al., 2003]. The study groups spent a mean of $0.14 \pm 0.03$ of feeding time eating rao fruits, with seasonal peaks in consumption between March and July and between October and December in each year (Fig. 5). In months when rao was fruiting, siamangs spent about $50 \%$ of nonfig-fruit-feeding time and $33 \%$ of total fruit-feeding time eating rao fruits.

The third-most-commonly consumed siamang food was paitan flowers. Siamangs spent a mean of $0.07 \pm 0.02$ of their feeding time eating paitan flowers, and siamangs in groups $\mathrm{F}$ and $\mathrm{G}$ spent more time eating paitan flowers than rao fruits (Fig. 6). Consumption of paitan flowers is primarily responsible for a pronounced peak in flower-eating time in March 2002: siamangs spent a mean of $0.40 \pm 0.10$ of their feeding time eating paitan flowers in that month. No plant other than figs, rao, and paitan comprised more than $5 \%$ of siamang diets in this study.

\section{Plant Part Availability in the Research Area was not a Good Predictor of Siamang Diets}

Neither the proportion of trees producing ripe fruits nor the estimated total ripe-fruit crop was correlated with the proportion of time that siamangs spent feeding on fruits in the same month for any

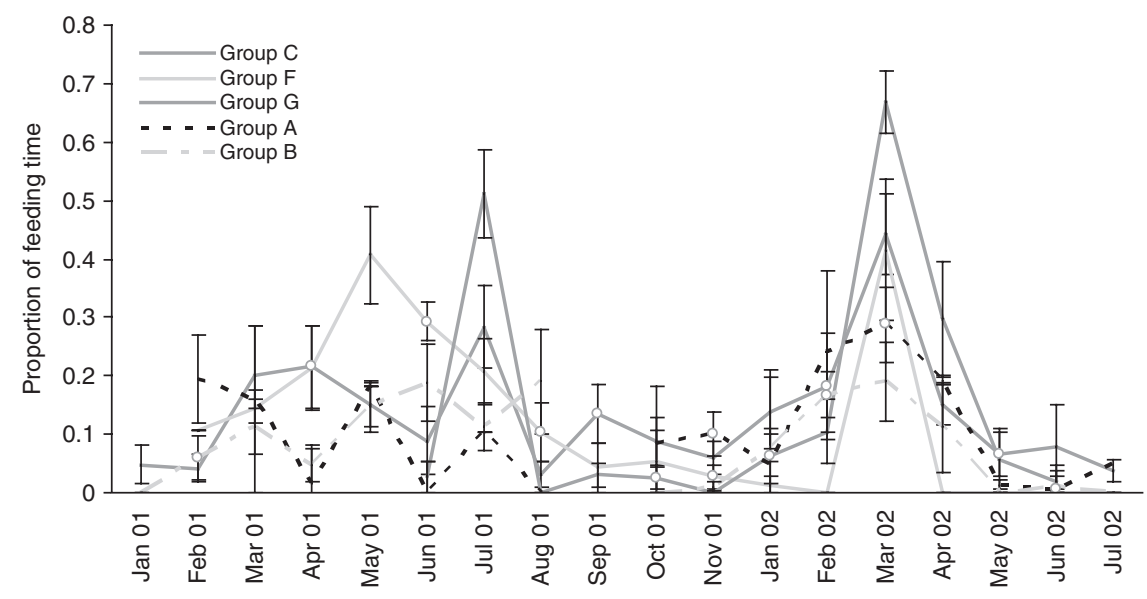

Fig. 3. Mean \pm SE proportion of feeding time that adults spent eating flowers. Circles indicate months from which data were missing. Data from the last 2 days before and the first 2 days after the missing month were substituted for missing data on the graph, but not in the analyses. 


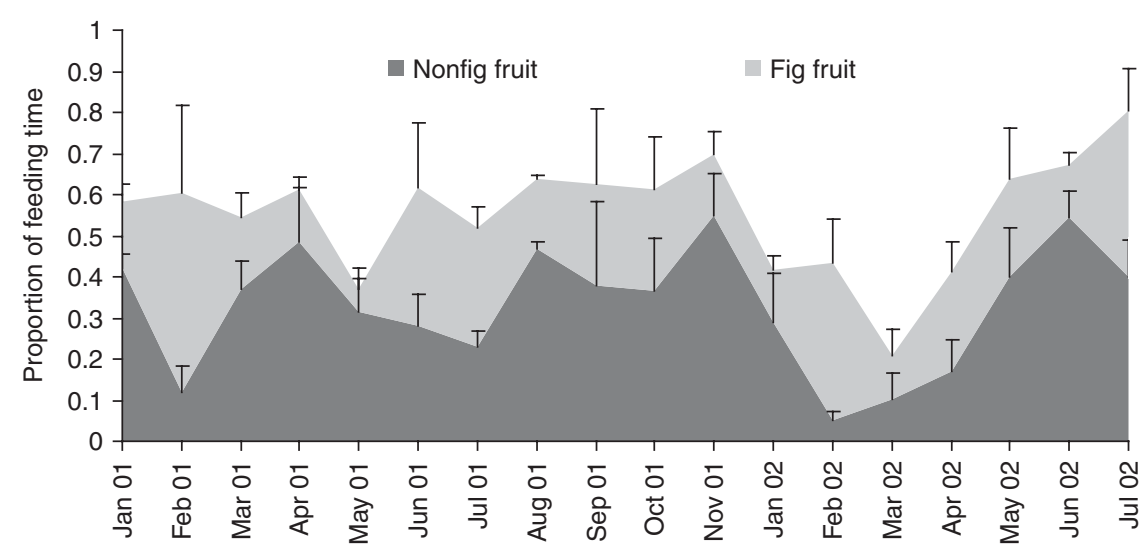

Fig. 4. Cumulative mean proportion of feeding time that adults in the study population spent feeding on fruits (fig and nonfig) in each month (mean of group means; error bars $=\mathrm{SE}$ ).

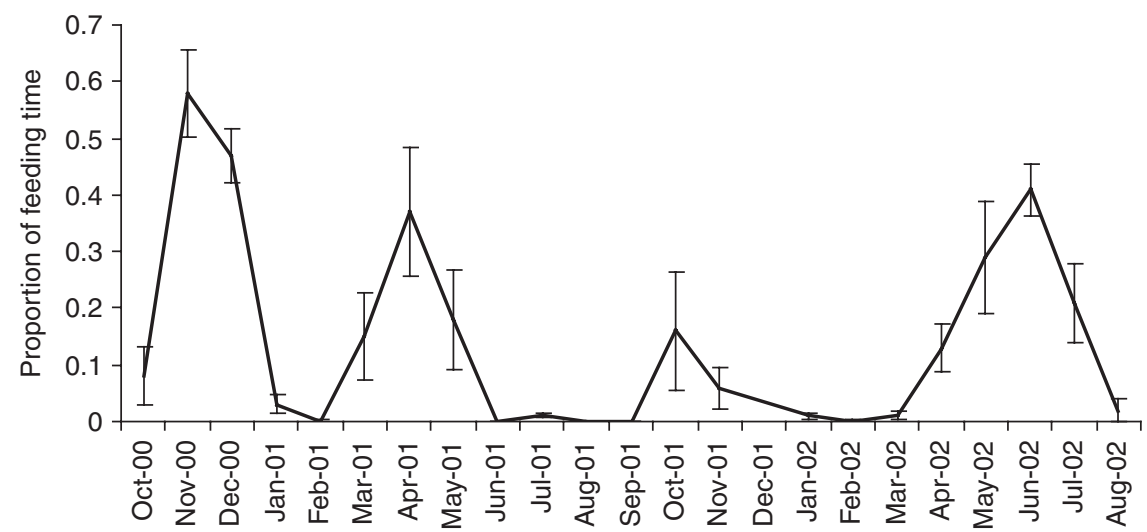

Fig. 5. Mean \pm SE proportion of feeding time that adults in the study population spent eating Dracontomelon dao fruits (means of group means).

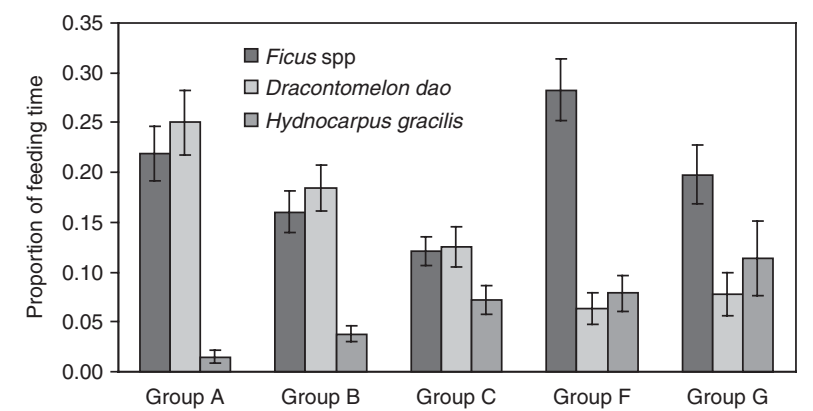

Fig. 6. Mean \pm SE proportion of feeding time that adults in each group spent eating the three most-commonly consumed plants. Plant parts eaten were: Ficus $\mathrm{spp}=75 \%$ fruit, $25 \%$ leaves, $<1 \%$ flowers; Dracontomelon dao= fruit; Hydnocarpus gracilis $=$ flowers.

group for nonfigs (proportion of trees producing ripe fruits: group A, $r_{s}=-0.433, N=9, P=0.244$; group $\mathrm{B}, \quad r_{s}=-0.050, \quad N=9, \quad P=0.898 ;$ group $\mathrm{C}$, $r_{s}=-0.127, N=11, P=0.709$; group $\mathrm{F}, r_{s}=-0.238$, $N=8, \quad P=0.570 ;$ group $\mathrm{G}, \quad r_{s}=0.100, \quad N=5$, $P=0.873$; total ripe-fruit crop: group $\mathrm{A}, r_{s}=0.233$, $N=9, \quad P=0.546 ;$ group $\mathrm{B}, \quad r_{s}=-0.067, \quad N=9$,
$P=0.865 ;$ group $\mathrm{C}, r_{s}=0.018, N=11, P=0.958$ group $\mathrm{F}, r_{s}=-0.143, N=8, P=0.736$; group $\mathrm{G}$, $r_{s}=-0.600, N=5, P=0.285$ ) or figs (proportion of trees producing ripe fruits: group $\mathrm{A}, r_{s}=0.563$, $N=9, \quad P=0.137 ;$ group $\mathrm{B}, \quad r_{s}=0.251, \quad N=9$, $P=0.515 ;$ group $\mathrm{C}, r_{s}=0.402, N=11, P=0.221$; group $\mathrm{F}, r_{s}=0.240, N=8, P=0.568 ;$ group $\mathrm{G}$, $r_{s}=0.300, N=5, P=0.624$; total ripe-fruit crop: group $\mathrm{A}, r_{s}=-0.500, N=9, P=0.170$; group $\mathrm{B}$, $r_{s}=0.500, N=9, P=0.170 ;$ group $\mathrm{C}, r_{s}=-0.427$, $N=11, P=0.190 ;$ group $\mathrm{F}, r_{s}=-0.667, \quad N=8$, $P=0.071$; group $\mathrm{G}, r_{s}=0.100, N=5, P=0.873$ ). There was also not a significant relationship between the availability of new leaves or flowers and the proportion of time spent feeding on that plant part for any group (group A, flowers $r_{s}=-0.050, N=9$, $P=0.898$; new leaves $r_{s}=-0.000, N=9, P=1.000$; group $\mathrm{B}$, flowers $r_{s}=-0.343, N=9, P=0.366$; new leaves $r_{s}=-0.467, N=9, P=0.205$; group $\mathrm{C}$, flowers $r_{s}=-0.355, N=11, P=0.285$; new leaves $r_{s}=0.209$, $N=11, P=0.537$; group $\mathrm{F}$, flowers $r_{s}=-0.431$, $N=8, P=0.286 ; \quad$ new leaves $r_{s}=0.095, \quad N=8$, $P=0.823 ;$ group $\mathrm{G}$, flowers $r_{s}=0.154, \quad N=5$, $P=0.805$; new leaves $r_{s}=0.300, N=5, P=0.624$ ). 
This is not surprising, as general availability of plant parts from all species in the Research Area is unlikely to accurately reflect the actual availability of important plant foods within the home range of each study group.

\section{Paitan Flowers were Available in the Study Area in most Months}

The estimated local density of paitan trees with $>10 \mathrm{~cm} \mathrm{DBH}$ in the study area was 3.4 individuals per hectare, or 1.7 male individuals per hectare [Kinnaird \& O'Brien, unpublished data]. Given a mean home range size of 19.5 ha for siamangs in healthy forests at Way Canguk [O'Brien et al., 2003], each home range should contain approximately 33 male paitan trees with $>10 \mathrm{~cm}$ DBH.

After individuals known to be females were excluded, an average of $16.0 \pm 2.0 \%$ of paitan trees in the phenology plots flowered per month $(N=15$ months), and at least one tree flowered in 14 of the 15 months from which data are available, but only 4 of 15 individuals (26.7\%) ever flowered: two individuals produced flowers in 10 months, one produced flowers in 13 months, and the fourth individuals flowered in only 1 month. If these flowering rates are typical and if male and female trees have similar flowering phenology, then each siamang home range in the study area should contain approximately six to eight male paitan trees that flower regularly.

\section{Flower Consumption was Highest when Fruit Consumption was Lowest}

Fig and nonfig fruits were the largest component of siamang diets, but the proportion of siamang feeding time spent feeding on fruits varied over time. The total proportion of feeding time that siamangs at Way Canguk spent feeding on fruits (fig and nonfig) was highest in July $2002(0.80 \pm 0.04)$ and lowest in March $2002(0.21 \pm 0.04)$. As gibbons generally prefer ripe fruits as foods, it is reasonable to assume that fruit-feeding time is related at least in part to the availability of preferred fruit species. Time spent eating fruit is necessarily time not spent eating flowers. Therefore, I used the ratio of the proportion of feeding time spent eating flowers to the proportion of feeding time spent feeding on foods other than fruits $\left(\mathrm{FL}_{\text {ratio }}\right)$ to explore the relationship between fruit-feeding time (used here as a rough index of the availability of preferred fruit species) and flowereating time. There was a significant negative relationship between mean fruit-feeding time and the $\mathrm{FL}_{\text {ratio }}$ in the same month for four of the five groups (group A, $r_{s}=-0.747, N=13, P=0.003$; group $\mathrm{B}, r_{s}=-0.587, N=15, P=0.024$; group $\mathrm{F}$, $r_{s}=-0.668, N=14, P=0.009$; group $\mathrm{G}, r_{s}=-0.669$, $N=10, P=0.035$; but not group C, $r_{s}=-0.247$, $N=16, P=0.356)$. This suggests that as fruitfeeding time (and presumably, ripe-fruit availability) declines, the contribution of flowers to siamang diets generally increases.

\section{A Shift from Fruit to Flower Consumption was Associated with Reduced DPL and Increased Feeding Time}

To evaluate the effect of a shift from heavy reliance on nonfig fruits to extensive flower feeding on overall activity patterns, I classified days into six classes for each plant part based on the proportion of feeding time spent eating that plant part on that day $(\leq 0.1=$ class $1,>0.1$ and $\leq 0.2=$ class $2,>0.2$ and $\leq 0.3=$ class $3,>0.3$ and $\leq 0.4=$ class $4,>0.4$ and $\leq 0.5=$ class $5, \quad>0.5=$ class 6$)$. General linear models (GLM) of the relationship between time spent eating nonfig fruits or flowers and DPL, with DPL as the dependent variable and the plant part feeding class and group as factors found no significant effect of group (flowers: $F_{4,7.9}=3.061$, $P=0.084$; nonfig fruits: $F_{4,22.3}=1.822, P=0.160$ ), or the interaction of group and feeding class (flowers: $F_{7,42}=0.432, P=0.882$; nonfig fruits: $F_{15,33}=0.725$, $P=0.743)$ on mean DPL, but a significant effect of flower and nonfig fruit-feeding class (flowers: $F_{4,20.8}=5.915, \quad P=0.002$; nonfig fruits: $\left.F_{5,21.8}=11.210, P<0.001\right)$ on DPL. As the proportion of feeding time spent feeding on flowers increased and the proportion of time spent feeding on nonfig fruits decreased, the DPL decreased (Fig. 7).

I also conducted analyses of the effects of the proportion of time spent feeding on flowers or nonfig fruits on total feeding time using GLM with the mean proportion of time spent feeding as the dependent variable and group and the feeding class for the relevant plant part (classes as above) as factors. In the analysis of the relationship between flower feeding and total feeding time, there was not a significant effect of group $\left(F_{4,8.2}=0.948, P=0.483\right)$ or flower-feeding class $\left(F_{4,10.2}=1.865, P=0.192\right)$ on total feeding time, but there was a significant effect of the interaction of group and flower-feeding class $\left(F_{8,51}=2.746, P=0.013\right)$. Separate analyses for each group did not detect significant effects of flowerfeeding class on total feeding time for any group (group A, $F_{2,9}=3.864, P=0.062 ;$ group $\mathrm{B}$, $F_{1,13}=0.241, P=0.632 ;$ group $\mathrm{C}, \quad F_{3,12}=2.661$, $P=0.096$; group $\mathrm{F}, F_{3,11}=1.639, P=0.237$; group $\mathrm{G}, F_{3,6}=3.649, P=0.083$ ), although several results approached significance. In an analysis of the relationship between nonfig fruit-feeding time and total feeding time, there was not a significant effect of the interaction between group and nonfig fruitfeeding class $\left(F_{16,42}=0.693, P=0.785\right)$, but there were significant effects of both group $\left(F_{4,27.2}=2.785\right.$, $P=0.047)$ and nonfig fruit-feeding class $\left(F_{5,24.9}=2.621, P=0.049\right)$. As the proportion of time spent feeding on nonfig fruits increased, the total feeding time decreased. 

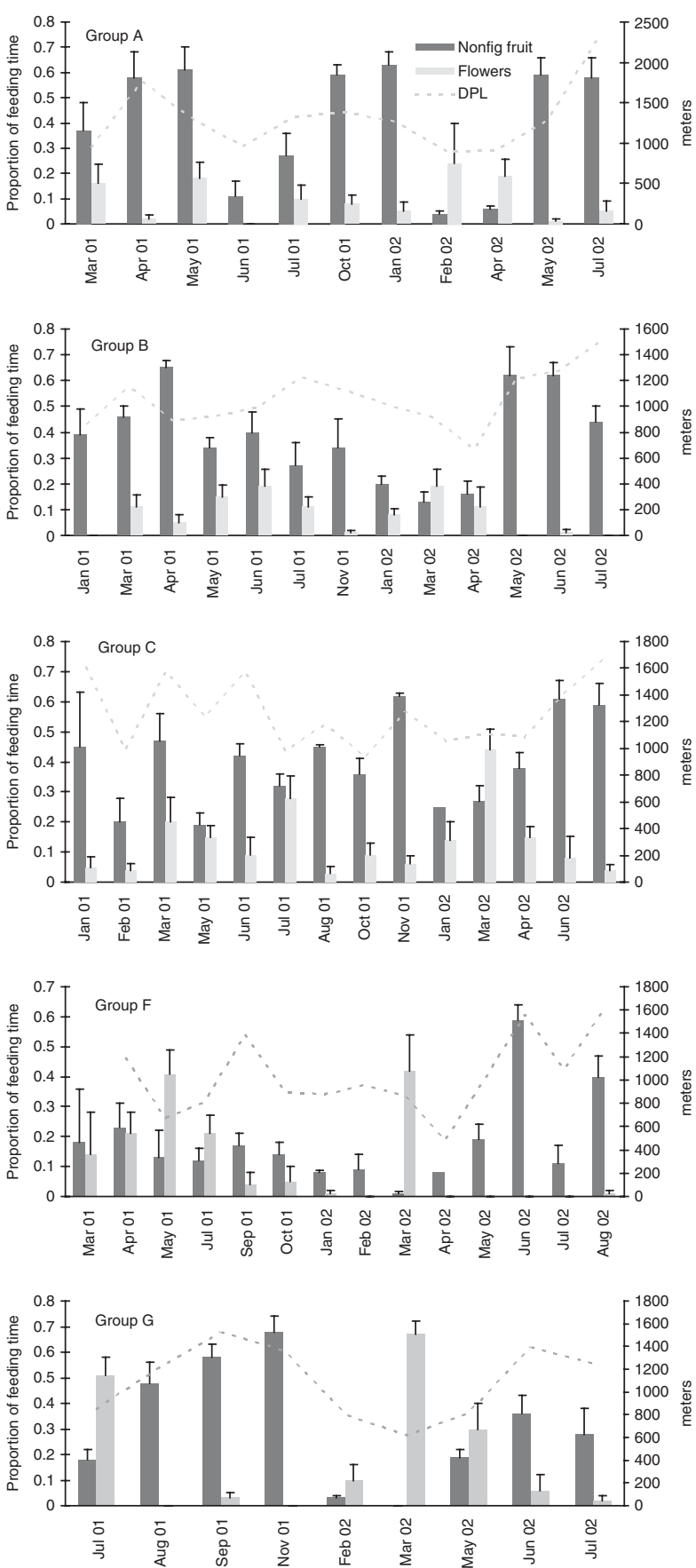

Fig. 7. Daily path length and nonfig fruit- and flower-feeding time in each group (mean $\pm \mathrm{SE})$.

I used a multivariate GLM to assess the relative importance of changes in flower-feeding time and nonfig fruit-feeding time in producing the observed shift in activity patterns associated with changes in diet (model: DPL $F_{6,57}=10.897, P<0.001$; feeding time $F_{6,57}=6.383, P<0.001$ ). There was a significant effect of nonfig-feeding class on DPL $(F=35.335$, $\mathrm{df}=1, P<0.001)$ and feeding time $(F=13.428$, $\mathrm{df}=1, P=0.001)$ and a significant effect of group on feeding time $(F=3.827, \mathrm{df}=4, P=0.009)$, but no significant effect of flower-feeding class on either variable (DPL: $F=1.107, \mathrm{df}=1, P=0.298$, feeding time: $F=0.504, \mathrm{df}=1, P=0.841)$ and no significant effect of group on DPL $(F=2.134$, $\mathrm{df}=4, P=0.090)$. These results suggest that changes in nonfig fruitfeeding time, rather than changes in flower-feeding time, drove the observed shift in overall activity patterns. As nonfig fruit-feeding time increased, DPL increased, and total feeding time decreased.

\section{DISCUSSION}

Siamangs at Way Canguk spent substantially more time eating flowers than most other gibbon populations [Bartlett, 2007; Elder, 2009], ate flowers in most study months, and spent over $40 \%$ of feeding time feeding on flowers in March 2002. Flowers comprised a similar proportion of siamang diets in another study at Way Canguk from January 2000 to December 2001 [Nurcahyo, 2001]. Therefore, despite pronounced variation in flower-feeding time across months, siamangs at Way Canguk consistently spent $\sim 12 \%$ of annual feeding time eating flowers across a 31-month period, which suggests that recurrent episodes of heavy reliance on flowers are probably typical for Way Canguk siamangs. Paitan, from which only flowers were eaten, was the third-mostcommonly consumed plant at Way Canguk. Paitan comprised $56 \%$ of the flowers eaten on average, and up to $100 \%$ during the months of heaviest flower consumption. Although the nutritional characteristics of paitan flowers are not known, these observations suggest that siamangs at Way Canguk rely heavily on paitan flowers as energy sources during some periods.

Nutritional analyses of paitan flowers have not yet been conducted, but flowers of other species consumed by primates have been reported to contain moderate to high percentages of protein (14-33\% of dry mass) and fiber [Oftedal, 1991; Simmen et al., 2007], but soluble sugar contents varied from relatively low [ 4\%, Simmen et al., 2007] to levels approaching those found in ripe fruits $[\sim 20 \%$, McCabe \& Fedigan, 2007]. Further information about the nutritional quality of siamang plant foods, including flowers, would be helpful in understanding the mechanisms driving food choice in this species.

Marshall and Wrangham [2007] distinguish important foods-those that comprise a substantial component of the diet-from preferred foods-those that are overselected relative to abundance. One of the primary limitations of this study is the absence of detailed phenological information reflecting the availability of plant foods in the home range of each siamang group. However, some preliminary conclusions about siamang food preferences can be drawn. Fig fruits are the top diet item for siamangs at Way Canguk [Kinnaird \& O'Brien, 2005; this study], and 
from July 1997 to January 2002, figs represented only $2.7 \%$ of fruiting trees in the Way Canguk Research Area, yet fig fruits comprised $>40 \%$ of the fruit component of siamang diets [Kinnaird \& O'Brien, 2005]. Therefore, figs appear to be overselected relative to the density of fruiting trees in the study area. However, figs at Way Canguk produce enormous fruit crops that comprise $>64 \%$ of the fruit crop and $41 \%$ of fruit biomass in the study area [Kinnaird \& O'Brien, 2005]. Therefore, figs are not overselected relative to their contribution to fruit biomass. Conversely, rao trees produce a relatively small proportion of the total fruit crop in the forest and represent a small proportion of fruiting trees [Kinnaird \& O'Brien, 2005], yet when rao fruits were available, they comprised about $50 \%$ of the nonfig fruits eaten by siamangs, which suggests a strong preference for rao fruits.

Do siamangs at Way Canguk also prefer paitan flowers? Relative to other flower species, the answer is clearly yes. Paitan individuals comprised $<1.3 \%$ of flowering trees in the phenology plots in every month, yet the majority of flowers consumed by siamangs in this study were from this species. However, flowers in general are not a preferred class of siamang food. Phenological data reflecting the availability of specific plant foods in the ranges of specific groups would be required to test the hypothesis that paitan flowers are preferred siamang foods, but the available data suggest that while paitan flowers are important, they may be less preferred than preferred nonfig fruits. Paitan flowers were included in the diet of at least one study group in most months, and the phenological data suggest that some individual plants produce flowers in most months of the year, yet the proportion of feeding time that siamangs spent eating paitan flowers varied dramatically over time, which should not be expected if siamangs seek out paitan flowers whenever they are available. Phenological data are not available beyond January 2002, but my subjective impression was that the peak in flower consumption in March 2002 was associated with unusually low fruit availability, but not with an obvious change in flower availability. During that month, most nonfig fruit species frequently consumed by siamangs were not fruiting, and the siamangs spent a mean of only $0.10 \pm 0.06$ of their feeding time eating nonfig fruits and $0.10 \pm 0.07$ eating fig fruits. While siamangs are generally believed to heavily rely on leaves as fallback foods, the study groups spent as much of their time eating paitan flowers $(0.40 \pm 0.10$ of feeding time $)$ as leaves $(0.36 \pm 0.11)$ in March 2002 .

Bornean orangutans (Pongo pygmaeus) [Knott, 1998] and hybrid Bornean gibbons (H. muelleri $\times$ agilis/albibarbis) [McConkey et al., 2003] have been observed consuming large quantities of flowers during mast flowering events. While fruit availability is generally believed to be the main predictor of variation in gibbon diets, only flower availability was a strong predictor of gibbon diets at Barito Ulu, suggesting that flowers may be preferred gibbon foods, rather than fallback foods [McConkey et al., 2003]. Conversely, I did not find a significant effect of the overall availability of any plant part on siamang diets at Way Canguk, and an exploration of the relationships among dietary variables and activity patterns suggested that the proportion of time that siamangs spent eating nonfig fruit was the primary factor affecting siamang activity patterns. A switch from a fruit- to a flower-dominated diet was associated with reduced DPL, which suggests an energy minimization strategy consistent with the interpretation of flowers as a fallback food.

Gibbons do not prefer all fruits equally [McConkey et al., 2003]. Therefore, it is likely to be the availability of specific fruits, rather than overall fruit availability, that is the primary determinant of gibbon diets. Gibbons probably base their feeding decisions on the overall distribution and abundance of resources in the forest, which may vary in complex, unpredictable ways, especially in forests that experience periodic droughts and mast fruiting events associated with ENSO events [Curran \& Leighton, 2000; Kinnaird \& O'Brien, 2005]. Clearly, then, the relationships between the availability of specific plant foods and animal diets are likely to be complex and nonlinear, and the dichotomy between "preferred" and "fallback" foods may be overly simplistic.

Animals may affect plant populations and communities through their feeding habits. For example, gibbons are believed to be important seed dispersers for some plant species [McConkey, 2009], and some primates may act as pollinators [Ferrari \& Strier, 1992; Overdorff, 1992]. However, siamangs at Way Canguk consume (and thereby destroy) entire flowers, rather than simply extracting the nectar. Accordingly, flower feeding by siamangs is likely to negatively affect reproductive success for individual plants. Siamangs only preyed on male flowers of this dioecious plant species. Therefore, assuming that pollination is relatively efficient in this species, even substantial flower consumption by siamangs may not result in reduced fruit set or a depressed population growth rate for the local population of paitan.

The primate community at Way Canguk includes five other diurnal species in addition to siamangs: Hylobates agilis, Macaca fascicularis, M. nemestrina, Presbytis melalophos, and Trachypithecus auratus. These species, especially the hylobatid $H$. agilis, are predicted to show substantial dietary overlap with siamangs, and other primates were frequently observed feeding on important siamang foods during this study and other studies at Way Canguk [A. Elder, unpublished data]. Other vertebrates, especially birds and squirrels, may also 
be important competitors with gibbons for fruits [Marshall et al., 2009]. Animals should adjust their foraging patterns in response to variation in the quantities of foods produced, but also in response to variation in the intensity of competition with other species for access to those foods, which will be affected in turn by the abilities of competitors to obtain and process foods with different characteristics [Robinson \& Wilson, 1998]. Previous studies of Asian apes suggest that the responses of sympatric species to low availability of preferred foods may differ dramatically. For example, the diets of sympatric gibbons ( $H$. albibarbis) and orangutans ( $P$. pygmaeus) in Borneo overlap up to $95 \%$ in periods of high fruit availability, but the two species display widely divergent fallback strategies [Dominy et al., 2008], with orangutans shifting to lower quality and harder-to-process foods, such as pith and bark [Knott, 1998], while gibbons range further in pursuit of soft fruits [Dominy et al., 2008] and rely heavily on fruits found in small patches [McConkey, 2009]. Periodic food shortages may have profound effects on reproduction. For example, female orangutans in the Gunung Palung National Park on Borneo and white-handed gibbons at Khao Yai National Park in Thailand show reduced conception rates during periods of low fruit availability [Knott, 1999; Savini et al., 2008]. However, the available evidence from siamangs at Way Canguk does not suggest reproductive seasonality, although females in healthy forest at Way Canguk have slightly shorter interbirth intervals than females in firedamaged habitat [O'Brien et al., 2003], which suggests that persistent low food availability may negatively affect female fertility. At Way Canguk, the density of siamangs is much higher than that of the sympatric hylobatid $H$. agilis [O'Brien et al., 2003], and from 1997 to $2007 \mathrm{H}$. agilis group numbers declined because of the high mortality and low reproduction in years with high temperature and low rainfall, whereas siamang group sizes increased and group numbers remained stable [O'Brien et al., 2008]. These data suggest that siamangs at Way Canguk are better able to withstand short-term variation in food availability than $H$. agilis, which may indicate that siamangs have a more effective fallback strategy than $H$. agilis. Alternatively, siamangs may competitively exclude smaller gibbons from feeding trees when food is scarce. The latter hypothesis is being examined in an ongoing study by Alice Elder.

The density of siamangs at Way Canguk is much higher than those at Ketambe or Kuala Lompat, the sites of other long-term siamang studies [O'Brien et al., 2004]. Siamangs rely heavily on ripe fig fruits at all three sites, and siamangs at Ketambe and Kuala Lompat have also been observed eating rao fruits [Chivers, 1974; Palombit, 1997]. However, rao fruits did not comprise a substantial part of siamang diets at
Ketambe or Kuala Lompat, and consumption of paitan flowers was not reported at either site [Chivers, 1974; Palombit, 1997]. The apparent preference for paitan at Way Canguk suggests that paitan flowers may be nutritionally superior to other flowers or may offer other advantages, such as greater ease of handling, larger patch size, or better digestibility. If paitan flowers are nutritionally inferior to preferred fruits, but contain more usable energy than leaves, the most common siamang fallback food, then use of these flowers during brief periods of low fruit availability, perhaps coupled with a reduction in foraging movements, may allow siamangs at Way Canguk to avoid or minimize energetic stress. Alternatively, if paitan flowers are preferred, energy-rich foods, then they may be of particular importance to siamangs because of their availability in most months. Accordingly, it is possible that the relatively high local densities of rao and paitan trees may be among the factors allowing siamangs to achieve high densities in the Way Canguk Research Area.

\section{ACKNOWLEDGMENTS}

Permission to conduct research in Indonesia was granted by the Indonesian Institute of Sciences (LIPI), and the Indonesian Ministry of Forestry's Department for the Protection and Conservation of Nature (PHKA). This research was conducted in full compliance with Indonesian laws. The American-Indonesian Exchange Foundation, Universitas Indonesia and WCS-IP provided logistical assistance in Indonesia, and Anton Nurcayho, Maya Dewi Prasetyaningrum, Teguh Priyanto, Tedy Presetya Utama, Janjiyanto, Sutarmin, Martin Trisunu Wibowo, and Abdul Roshyd provided assistance in the field. The author thanks Mohammad Iqbal for his assistance with plant identification, and Margaret Kinnaird and Tim O'Brien for sharing unpublished data and for many helpful discussions. Alice Elder and two anonymous reviewers provided helpful suggestions that substantially improved this manuscript.

\section{REFERENCES}

Bartlett TQ. 2007. The Hylobatidae: small apes of Asia. In: Campbell CJ, Fuentes A, MacKinnon KC, Panger M, Bearder SK, editors. Primates in perspective. New York: Oxford University Press. p 274-289.

Chivers DJ. 1974. The siamang in Malaya: a field study of a primate in tropical rain forest. In: Kuhn H, Luckett WP, Noback CR, Schultz AH, Starck D, Szalay FS, editors. Basel: Karger. 335p.

Chivers DJ, Raemaekers JJ. 1986. Natural and synthetic diets of Malayan gibbons. In: Else JG, Lee PC, editors. Primate ecology and conservation. Cambridge: Cambridge University Press. p 39-56.

Clutton-Brock TH, Harvey PH. 1977. Species differences in feeding and ranging behaviour in primates. In: Clutton-Brock TH, editor. Primate ecology: studies of 
feeding and ranging behaviour in lemurs, monkeys and apes. London: Academic Press. p 557-579.

Curran LM, Leighton M. 2000. Vertebrate responses to spatiotemporal variation in seed production of mast-fruiting Dipterocarpaceae. Ecol Monogr 70:101-128.

Dominy NJ, Vogel ER, Haag L, van Schaik CP, Parker GG. 2008. Fallback or fall forward: food dispersion, canopy complexity, and the foraging adaptations of apes in Southeast Asia. Am J Phys Anthropol S46: 91-92.

Elder AA. 2009. Hylobatid diets revisited: the importance of body mass, fruit availability, and interspecific competition. In: Lappan S, Whittaker DJ, editors. The gibbons: new perspectives on small ape socioecology and population biology. New York: Springer.

Ferrari SF, Strier KB. 1992. Exploitation of Mabea fistulifera nectar by marmosets (Callithrix flaviceps) and muriquis (Brachyteles arachnoides) in south-east Brazil. J Trop Ecol 8:225-239.

Goldizen AW, Terborgh J, Cornejo F, Porras DT, Evans R. 1988. Seasonal food shortage, weight loss, and the timing of births in saddle-back tamarins (Saguinus fuscicollis). J Anim Ecol 57:839-901.

Janson CH, Chapman CA. 1999. Resources and primate community structure. In: Fleagle JG, Janson C, Reed KE, editors. Primate communities. Cambridge: Cambridge University Press. p 237-267.

Janzen DH. 1979. How to be a fig. Annu Rev Ecol Syst $10: 13-52$.

Kinnaird MF, O'Brien TG. 2005. Fast foods of the forest: the influence of figs on primates and hornbills across Wallace's Line. In: Dew JL, Boubli JP, editors. Tropical fruits and frugivores: the search for strong interactors. New York: Springer. p 155-184.

Knott CD. 1998. Changes in orangutan diet, caloric intake and ketones in response to fluctuating fruit availability. Int $\mathrm{J}$ Primatol 19:1061-1079.

Knott CD. 1999. Reproductive, physiological, and behavioral responses of orangutans in Borneo to fluctuations in food availability. Cambridge, MA: Harvard University. 355p.

Lambert JE. 2007a. Primate nutritional ecology: feeding biology and diet at ecological and evolutionary scales. In: Campbell CJ, Fuentes A, MacKinnon KC, Panger M, Bearder SK, editors. Primates in perspective. Oxford, UK: Oxford University Press. p 482-495.

Lambert JE. 2007b. Seasonality, fallback strategies, and natural selection: a chimpanzee and cercopithecoid model for interpreting the evolution of hominin diet. In: Ungar PS, editor. Evolution of the human diet: the known, the unknown, and the unknowable. Oxford: Oxford University Press. p 324-343.

Lappan S. 2008. Male care of infants in a siamang (Symphalangus syndactylus) population including socially monogamous and polyandrous groups. Behav Ecol Sociobiol 62:1307-1317.

Lappan S. 2009. Patterns of infant care in wild siamangs (Symphalangus syndactylus) in southern Sumatra. In: Lappan S, Whittaker DJ, editors. The gibbons: new perspectives on small ape socioecology and population biology. New York: Springer.

Leighton DR. 1987. Gibbons: territoriality and monogamy. In: Smuts BB, Cheney DL, Seyfarth RM, Wrangham RW, Struhsaker TT, editors. Primate societies. Chicago: University of Chicago Press. p 135-145.

Leighton M. 1993. Modeling dietary selectivity by Bornean orangutans: evidence for integration of multiple criteria in fruit selection. Int $J$ Primatol 14:257-313.

MacKinnon JR, MacKinnon KS. 1980. Niche differentiation in a primate community. In: Chivers DJ, editor. Malayan forest primates: ten years' study in tropical rain forest. New York: Plenum.

Marshall AJ, Wrangham RW. 2007. The ecological significance of fallback foods. Int J Primatol 28:1219-1235.

Marshall AJ, Cannon CH, Leighton M. 2009. Competition and niche overlap between gibbons (Hylobates albibarbis) and other frugivorous vertebrates in Gunung Palung National Park, West Kalimantan, Indonesia. In: Lappan S, Whittaker DJ, editors. The gibbons: new perspectives on small ape socioecology and population biology. New York: Springer.

McCabe GM, Fedigan LM. 2007. Effects of reproductive status on energy intake, ingestion rates, and dietary composition of female Cebus capucinus at Santa Rosa, Costa Rica. Int J Primatol 28:837-851.

McConkey KR. 2009. The seed dispersal niche of gibbons in Bornean dipterocarp forests. In: Lappan S, Whittaker DJ, editors. The gibbons: new perspectives on small ape socioecology and population biology. New York: Springer.

McConkey KR, Aldy F, Ario A, Chivers DJ. 2002. Selection of fruit by gibbons (Hylobates muelleri $\times$ agilis) in the rain forests of central Borneo. Int J Primatol 23:123-145.

McConkey KR, Ario A, Aldy F, Chivers DJ. 2003. Influence of forest seasonality on gibbon food choice in the rain forests of Barito Ulu, central Kalimantan. Int J Primatol 24:19-32.

Ménard N, Vallet D. 1997. Behavioral responses of Barbary macaques (Macaca sylvanus) to variations in environmental conditions in Algeria. Am J Primatol 43:285-304.

Nurcahyo A. 2001. Jelajah harian, daerah jelejah, pakan dan makan serta calling pada siamang (Hylobates syndactylus). Bogor: Wildlife Conservation Society-Indonesia Program. p 39-56.

O'Brien TG, Kinnaird MF, Dierenfeld ES, Conklin-Brittain NL, Wrangham RW, Silver SC. 1998. What's so special about figs? Nature 392:668.

O'Brien TG, Kinnaird MF, Anton N, Prasetyaningrum MDP, Iqbal M. 2003. Fire, demography and the persistence of siamang (Symphalangus syndactylus: Hylobatidae) in a Sumatran rain forest. Anim Conserv 6:115-121.

O'Brien TG, Kinnaird MF, Anton N, Iqbal M, Rusmanto M. 2004. Abundance and distribution of sympatric gibbons in a threatened Sumatran rain forest. Int J Primatol 25:267-284.

O'Brien TG, Kinnaird MF, Nurcahyo A, Nusalawo M. 2008. Response of siamang and agile gibbons to climate fluctuations in Indonesia. XXII Congress of the International Primatological Society. Edinburgh, Scotland.

Oftedal OT. 1991. Nutrition and foraging in primates. Philos Trans R Soc Lond B Biol Sci 334:161-170.

Overdorff DJ. 1992. Differential patterns in flower feeding by Eulemur fulvus rufus and Eulemur rubriventer in Madagascar. Am J Primatol 28:191-203.

Palombit RA. 1997. Inter- and intra-specific variation in the diets of sympatric siamang (Hylobates syndactylus) and lar gibbons (Hylobates lar). Folia Primatol 68:321-337.

Raemaekers JJ. 1977. Gibbons and trees: comparative ecology of the siamang and lar gibbons [unpublished Ph.D. thesis]. Cambridge: University of Cambridge.

Raemaekers JJ. 1984. Large versus small gibbons: relative roles of bioenergetics and competition in their ecological segregation in sympatry. In: Preuschoft H, Chivers DJ, Brockelman WY, Creel N, editors. The lesser apes: evolutionary and behavioral biology. Edinburgh: Edinburgh University Press. p 209-218.

Robinson BW, Wilson DS. 1998. Optimal foraging, specialization, and a solution to Liem's Paradox. Am Nat 151:223-235.

Savini T, Boesch C, Reichard U. 2008. Home-range characteristics and the influence of seasonality on female reproduction in white-handed gibbons (Hylobates lar) at Khao Yai National Park, Thailand. Am J Phys Anthropol 135:1-12. 
Flowers Are an Important Food for Small Apes / 635

Simmen B, Bayart F, Marez A, Hladik A. 2007. Diet, nutritional ecology, and birth season of Eulemur macaco in an anthropogenic forest in Madagascar. Int J Primatol 28:1253-1266.
Terborgh J. 1983. Five new world primates: a Study in comparative ecology. Princeton: Princeton University Press. Terborgh J, Stern M. 1987. The surreptitious life of the saddlebacked tamarin. Am Sci 75:260-269. 